\title{
Assessing the effect of multidimensional family therapy in adolescents on police arrests against a background of falling crime rates. $A$ randomised controlled trial with 7-year follow-up
}

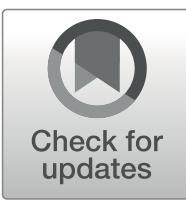

\author{
Thimo M. van der Pol ${ }^{1,2}$ - Moran D. Cohn ${ }^{2}$. Lieke van Domburgh ${ }^{2}$. \\ Henk Rigter ${ }^{1} \cdot$ Robert R. J. M. Vermeiren ${ }^{1,2}$
}

Published online: 2 May 2020

(C) The Author(s) 2020

\begin{abstract}
Background Earlier, we reported that multidimensional family therapy (MDFT) and cognitive behavioural therapy (CBT) decreased criminal offending in adolescents as measured with self-report in a randomised controlled trial with 1year follow-up. The present study tested if this effect could be confirmed using police arrest data.

Methods Study participants were 109 adolescents who were recruited for the Dutch part of a transnational treatment trial. National police arrest records were analysed for 3 years before the adolescents entered treatment with MDFT or CBT and for 7 years after treatment entry.
\end{abstract}

Results Police arrest rates rose in the 3 years preceding treatment and then dropped in both treatment groups to almost zero level during the follow-up period.

Conclusions The results suggest that MDFT and CBT both strongly and durably decreased police arrest rates. However, this conclusion remains uncertain as crime rates concurrently decreased in the general population.

Trial registration ISRCTN51014277

Keywords Criminality $\cdot$ Adolescents $\cdot$ Police arrest registry $\cdot$ Self-reported criminal offences $\cdot$ Multidimensional family therapy $\cdot$ Randomised controlled trial

Thimo M. van der Pol

thimovanderpol@gmail.com

Extended author information available on the last page of the article 


\section{Background}

Multidimensional family therapy (MDFT) is a comprehensive evidence-based treatment programme for improving both substance abuse and criminal offending outcomes in diverse adolescent populations and treatment delivery settings (Galanter et al. 2014; Liddle 2010; Van der Pol et al. 2017b). In most randomised controlled treatment trials, MDFT was pitched against effective "treatments as usual", including cognitive behavioural therapy (CBT). (Dakof et al. 2015; Hendriks et al. 2011; Liddle et al. 2011, 2009; Rigter et al. 2013).

In the studies cited, the effect of treatment on criminal behaviour was assessed from adolescents' self-reports of the crimes they had committed, apart from Dakof et al. (2015), who collected crime data from registries to complement the study participants' self-reports. Further, meta-analyses analysing criminal behaviour, comparing primarily CBT with systemic treatments; MDFT, multisystemic therapy (MST) and functional family therapy, reported slightly better results for the systemic treatments (Hartnett et al. 2017; Van der Pol et al. 2017b; Van der Stouwe et al. 2014). Both self-report and official record (arrests) studies were included in the meta-analyses.

The literature disagrees about the validity of self-reported criminal offences. Selfreport data may be biased, with respondents holding back on confessing all transgressions of the law. On the other hand, self-report may invite respondents to also mention criminal offences that went unnoticed to police and justice authorities (Kirk 2006). The alternative source of information, official record reports, may yield more objective information, but these databases often are incomplete (Kirk 2006).

To compare the two forms of assessing the prevalence of criminal offending - selfreport and registry-, we first carried out a self-report study among the Dutch and Swiss adolescents with a cannabis use disorder from the transnational INCANT trial (International Cannabis Need of Treatment study) (Rigter et al. 2010; Van der Pol et al. 2017). We followed these youths for 1 year after baseline, i.e. from the moment they entered randomly allocated treatment with either MDFT or the comparison treatment (CBT in the Hague, the Netherlands; less structured individual psychotherapy in Geneva, Switzerland). Half of all these adolescents said they had committed one or more criminal offences in 90 days before the baseline assessment. The proportion reporting to be nondelinquent in chunks of 90 days rose in the year after treatment entry, most so in the MDFT group. Furthermore, MDFT as hypothesized, yielder better results than the comparison therapy in reducing the number of violent offences among adolescents who reported a criminal offence history at baseline (Van der Pol et al. 2017a).

Next, we analysed registry data from the national police arrests database in the Netherlands. Subjects were the Dutch adolescents from INCANT. For these youths, arrest data were retrieved for 3 years preceding and 3 years following treatment entry. The number of police arrests which rose in 3 years before treatment was initiated and dropped sharply in 3 years thereafter, with no difference seen between MDFT and CBT in the follow-up period, possibly with exception of a property crime measure (Van Der Pol et al. 2018).

The database enabled us to extend the follow-up period from the usual 1 to 2 years in MDFT trials to 7 years. We reasoned that amassing more data from the trial would give more insight concerning the impact of the two treatment conditions. Our first aim of this study is to investigate if the obtained decrease of police arrests for the Dutch adolescents could be retained for a longer follow-up period. The second aim was to investigate if both treatments would differ in their retainment capability and to analyse whether baseline characteristics of 
the adolescent differentially predicted treatment effect — reduction of registered arrests - in MDFT and CBT. We hypothesized that MDFT would be better able to retain the low police arrest rates. Further, we did not expect any influence of baseline characteristics on treatment outcome.

\section{Methods}

\section{Sample}

The study included 109 adolescents from the Hague and the surrounding region in the Netherlands. All had a DSM-IV cannabis use disorder. They were between 13 and 18 years old (mean age 16.8 years). Eight in ten were boys. Seven in ten were of Dutch

Table 1 Baseline characteristics of study sample $(n=109)^{\text {a }}$

\begin{tabular}{|c|c|c|c|}
\hline & $\begin{array}{l}\text { MDFT }(n=55) \\
\text { Mean }(\mathrm{SD}) / \%\end{array}$ & $\begin{array}{l}\text { CBT }(n=54) \\
\text { Mean }(\mathrm{SD}) / \%\end{array}$ & $\begin{array}{l}\text { Total sample }(n=109) \\
\text { Mean }(\mathrm{SD}) / \%\end{array}$ \\
\hline \multicolumn{4}{|l|}{ Demographic background } \\
\hline Age (range $13-18$ years) (years) & $16.6(1.3)$ & $16.9(1.2)$ & $16.8(1.3)$ \\
\hline Gender male (\%) & $80.0 \%$ & $79.6 \%$ & $79.8 \%$ \\
\hline Ethnicity Dutch/western (\%) & $72.7 \%$ & $70.4 \%$ & $71.6 \%$ \\
\hline \multicolumn{4}{|l|}{ Delinquency ${ }^{b}$} \\
\hline Total offences $(\%)$ & $72.7 \%$ & $59.3 \%$ & $66.1 \%$ \\
\hline Misdemeanour offences (\%) & $10.9 \%$ & $11.1 \%$ & $11.0 \%$ \\
\hline Drug offences $(\%)$ & $0.0 \%$ & $7.4 \%$ & $3.7 \%$ \\
\hline Vandalism (\%) & $23.6 \%$ & $18.5 \%$ & $21.1 \%$ \\
\hline Property offences $(\%)$ & $45.5 \%$ & $42.6 \%$ & $44.0 \%$ \\
\hline Violent offences $(\%)$ & $45.5 \%$ & $50.0 \%$ & $47.7 \%$ \\
\hline Sexual offences $(\%)$ & $1.8 \%$ & $0.0 \%$ & $0.9 \%$ \\
\hline (attempted) Manslaughter (\%) & $5.5 \%$ & $1.9 \%$ & $3.7 \%$ \\
\hline Arson $(\%)$ & $0.0 \%$ & $1.9 \%$ & $0.9 \%$ \\
\hline (attempted) Murder (\%) & $0.0 \%$ & $0.0 \%$ & $0.0 \%$ \\
\hline Ever in prison $(\%)$ & $37.0 \%$ & $42.6 \%$ & $39.8 \%$ \\
\hline Sum severity score $^{d}(\mathrm{SD})$ & $15.4(16.9)$ & $17.4(19.9)$ & $16.4(18.4)$ \\
\hline \multicolumn{4}{|l|}{ DSM-IV diagnosis (past year) } \\
\hline Conduct disorder (CD) $(\%)$ & $34.8 \%$ & $22.9 \%$ & $28.7 \%$ \\
\hline Oppositional deviant disorder (ODD) (\%) & $19.6 \%$ & $14.9 \%$ & $17.2 \%$ \\
\hline CD and/or ODD (\%) & $43.5 \%$ & $31.9 \%$ & $37.6 \%$ \\
\hline
\end{tabular}

${ }^{a} M D F T$ multidimensional family therapy; $C B T$ cognitive behavioural therapy; $S D$ standard deviation; $n$ number

b Offences committed before start of the treatment, as inferred from police arrest data

${ }^{c}$ Moderate, sizable and serious violent offences are included

${ }^{\mathrm{d}}$ Frequency of offences $\times$ severity score of offence using the BOOG-scale 
or another Western ethnicity (Van Der Pol et al. 2018). At the time of treatment entry, $66 \%$ had a police arrest history (for more information see Table 1).

The adolescents concerned were enrolled in the transnational INCANT trial. INCANT compared the effectiveness of MDFT and treatment as usual-CBT in the Hague - to reduce cannabis use and the prevalence of cannabis use disorder (Rigter et al. 2010). Apart from not meeting the broad inclusion criteria, adolescents were only excluded from the study if needing inpatient treatment (Rigter et al. 2010). Treatment sites were Parnassia Brijder (Mistral unit; addiction care) and De Jutters (Palmhuis unit; forensic care).

\section{Treatments}

CBT, the cognitive-behavioural therapy protocol developed by Korrelboom et al. (Korrelboom and Ten Broek 2004), was administered in this study; the treatment entails consistently involving enhancement of treatment motivation, sessions with the individual adolescents (not with the parents except to inform them on treatment progress) and relapse prevention, for a full description of the treatment protocol see Rigter et al. (2010, 2013).

MDFT developed by Liddle $(2002,2010)$ consists of three stages. The first one focuses on intensively enhancing treatment motivation, building multiple therapeutic alliances and drafting the treatment plan. In stage 2, treatment plan interventions targeting the youth and his or her family are carried out, including education about adolescence, behavioural development and risk factors for problem behaviour, relapse prevention, improving family communication and relationships and strengthening parental educational skills. Stage 3 involves sealing off the treatment, agreeing on a relapse prevention plan and providing booster sessions if needed.

In INCANT, both MDFT and CBT were scheduled to last for 6 months. MDFT was administered in approximately two sessions per week - in roughly equal proportion to be held with the adolescent, parent(s) and family (adolescent and parent(s) together. In CBT, the number of sessions with the adolescent was matched to be similar to MDFT. Rowe et al. (2013) present details on the actual treatment dose received and the efforts made to evaluate and safeguard treatment integrity and fidelity.

\section{Procedures}

The research institute of the Ministry of Security and Justice of the Netherlands, the WODC, retrieved police arrest (with summons) records from the National Police Information Services database (IPOL) for all 109 adolescents for a period of 10 years, running from 3 years preceding treatment entry through 7 years thereafter. This covered the period 2003-2013 for the adolescents from the first year of recruitment for INCANT up to the period 2006-2016 for the last recruited adolescents (2010). For the flow diagram of the study, see van der Pol et al. (2018). Only one of the 109 adolescents dropped out from the trial during the follow-up period. 


\section{Measurements: criminal offences}

We categorized offences as violent crimes (aggression, violent sexual offences and violent property offences), property crimes and others. The Dutch BOOG scale was used to score offence severity (Mulder et al. 2010). This scale converts law codes into a 12-degree severity index, i.e. (1) misdemeanour; (2) drug offence; (3) vandalism; (4) property offence; (5-7) moderate, sizable or serious violent offence; (8) sexual offence; (9) child sexual offence; (10) (attempted) manslaughter; (11) arson and (12) (attempted) murder. To calculate a severity score for an adolescent, we multiplied for each year the registered crime(s) with the severity score of the crime(s). These time period ("time chunks") severity scores were used to analyse the crime trajectories of the adolescents.

\section{Measurements: cannabis use}

To record the frequency of consumption of cannabis, we applied the timeline follow-back (TLFB; Sobell and Sobell 1992), a calendar method to collect information on the adolescent's use of cannabis in 90 days before each assessment. Adolescents were classified as low-severity cannabis users if they took cannabis on fewer than 65 days (the baseline median value in the trial), and as high-severity users if they took the drug on 65 or more days. We delivered the adolescent diagnostic interview (ADI-Light; Winters and Henly 1993) to determine if the youth met the criteria for a cannabis use disorder.

\section{Measurements: possible treatment modifying factors}

Earlier studies suggested that some factors may alter the response to MDFT treatment. MDFT outperformed comparison therapy, including CBT, in reducing cannabis use problems especially in adolescents with a severe level of cannabis use at baseline (Henderson et al. 2010; Hendriks et al. 2011; Van der Pol et al. 2017b). In our present analyses, we maintained the distinction between low-severity and high-severity cannabis users (Van der Pol et al. 2017b). Other factors found to correlate with MDFT treatment superiority are the young age of the adolescent, the presence of an externalizing disorder and the level of family functioning (Hendriks et al. 2011). To examine if these latter factors mattered in the current study as well, we first administered the National Institute of Mental Health Diagnostic Interview Schedule for Children Version IV (NIMH DISC-IV; Shaffer et al. 2000) to determine if the adolescent had conduct disorder (CD) or oppositional defiant disorder (ODD) in the year before treatment entry. We evaluated family functioning with the Dutch version of the Family Environment Scale subscales Conflict and Cohesion (Grotevant and Carlson 1989; Jansma and De Coole 1995; Moos and Moos 1994)

\section{Statistical analyses}

Analyses were run with SPSSv24.0. The adolescent's first day of treatment was taken to retrospectively define the 3 pre-treatment years and the 7 years of follow-up. We carried out pairwise comparisons, with the log rank statistic, to identify differences between the MDFT and CBT conditions. We assessed group differences in police arrests, number of arrests at issue and the type and severity of these offences. The data for 3 years before and 7 years after treatment entry, respectively, were analysed with 
separate repeated measure general linear models (rmGLM) for frequency, type (violent and property offences) and severity of recorded offences.

Next, each pre-treatment year and each follow-up year was entered as a separate "chunk" in the analyses, as a within-subject variable. Treatment was handled as a between-subject variable. In addition, we ran moderator analyses to examine second-order interactions: age (both continuous and categorical (13-16 versus 17-18 years), history of crimes, baseline cannabis use rate (severe versus non-severe), of conduct disorder (CD) or oppositional defiant disorder (ODD) and family functioning. To account for any departures from sphericity, we applied Huynh-Feldt-corrected estimates if $\sum \geq 0.75$, and GreenhouseGeisser correction if $\sum<0.75$ applied in rmGLM analyses (Girden 1992).

\section{Results}

\section{Reasons for pre-treatment police arrests}

Of the total sample, $66.1 \%$ had been arrested at least once in 3 years before treatment entry. As reason for arrest, property crimes and violent crimes were most prevalent (see Table 1). The two treatment groups did not differ in distribution of offence categories, nor did they differ in criminal offending severity score; the sum score across this period was 16.4 (SD 18.4) for the total sample and 15.4 (16.9) and 17.4 (19.9) for the MDFT and CBT groups, respectively.

\section{Change in the total number of arrests}

The total number of police arrests increased across the 3 pre-treatment years and decreased after treatment entry (Fig. 1). According to rmGLM analyses, the number of arrests grew linearly in the pre-treatment period in both groups (time: Huynh-Feldt $\mathrm{F}_{1.7,178.5}=16.9$,

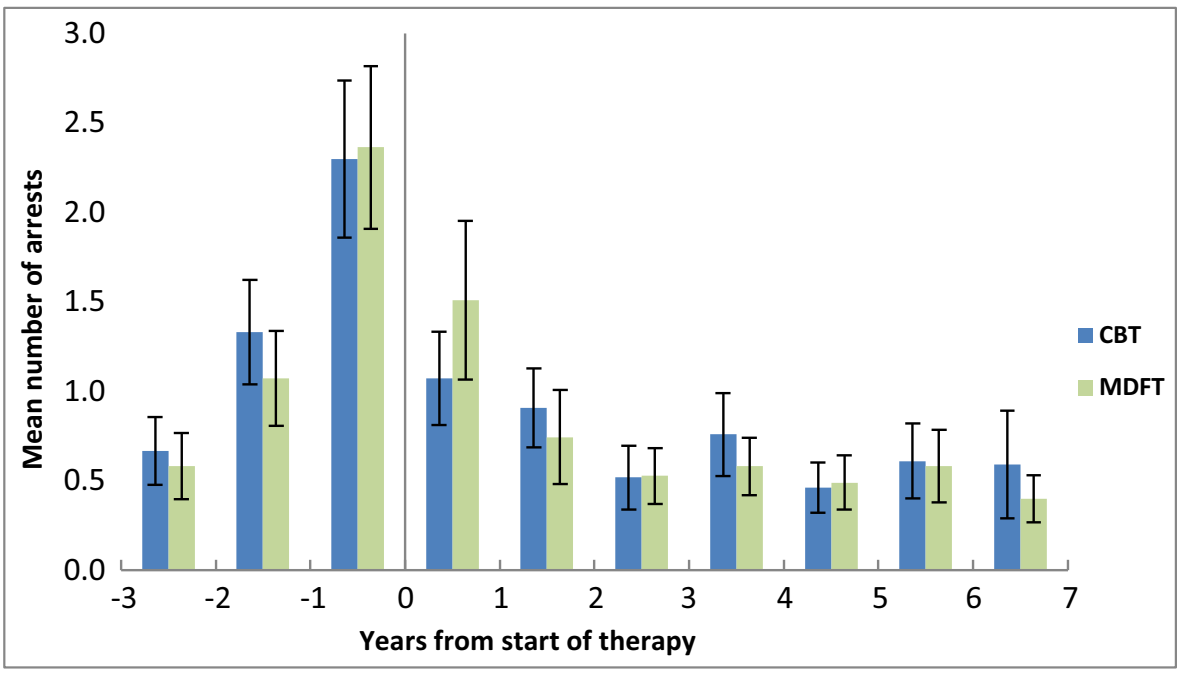

Fig. 1 Mean number of arrests per year from the start of CBT or MDFT. CBT= cognitive behavioural therapy; MDFT = multidimensional family therapy 
$p<0.001, \eta^{2}=0.14$; linear $\left.\mathrm{F}_{1,107}=32.1, p<0.001, \eta^{2}=0.23\right)$. The two groups did not differ on pre-treatment delinquency increase (Huynh-Feldt $\mathrm{F}_{1.7,178.5}=0.2, p=0.82, \eta^{2}=0.001$ ) or intercept $\left(\mathrm{F}_{1,107}=0.1, p=.76, \eta^{2}=0.001\right)$. In the 7 years of follow-up after treatment entry, the number of total offences fell to almost zero level (time: Greenhouse-Geisser $F_{3.8,403.4}=$ $14.5, p<0.0001, \eta^{2}=0.12$ ). The decline was similar in both treatment groups (GreenhouseGeisser $\mathrm{F}_{3.8,403.4}=0.4, p=0.82, \eta^{2}=0.03$ ).

\section{Change in severity of arrests}

The severity of the offences increased across the three pre-treatment years, from an average severity score of 2.06 (SD 5.08) to 8.07 (SD 11.8), in both groups to the same extent (time: Huynh-Feldt $\mathrm{F}_{1.7,178.7}=13.9, p<0.0001, \eta^{2}=0.12$, time*treatment: Huynh-Feldt $\left.F_{1.7,178.7}=0.11, p=.86, \eta^{2}=0.001\right)$. Group models did not differ in their intercepts $\left(\mathrm{F}_{1,107}=0.2, p=0.65, \eta^{2}=0.002\right)$. In the years after treatment entry, the offences became less severe (time: $\mathrm{F}_{3.5,375.9}=14.4, p<0.0001, \eta^{2}=0.12$ ). The decline in severity followed a quadratic trajectory (linear: $\mathrm{F}_{1,107}=51.5, p<0.001$, $\eta^{2}=0.33$; quadratic: $\mathrm{F}_{1,107}=20.3, p<0.001, \eta^{2}=0.16$ ), with a severity score of 1.76 (SD 4.23) in the third year after the start of treatment, which remained low up until the seventh year after treatment 1.46 (SD 4.98), with no difference in intercept $\left(\mathrm{F}_{1,107}<\right.$ $0.001, p=0.99, \eta^{2}<0.001$ ) or decline rate (Greenhouse-Geisser $\mathrm{F}_{3.5,375.9}=0.65, p=$ $\left.0.61, \eta^{2}=0.01\right)$ noted between the treatment groups.

\section{Violent and property offences}

With the same set of analyses, we targeted violent and property crimes, respectively. In the follow-up period, both types of offences dropped in number: violent (Greenhouse-Geisser

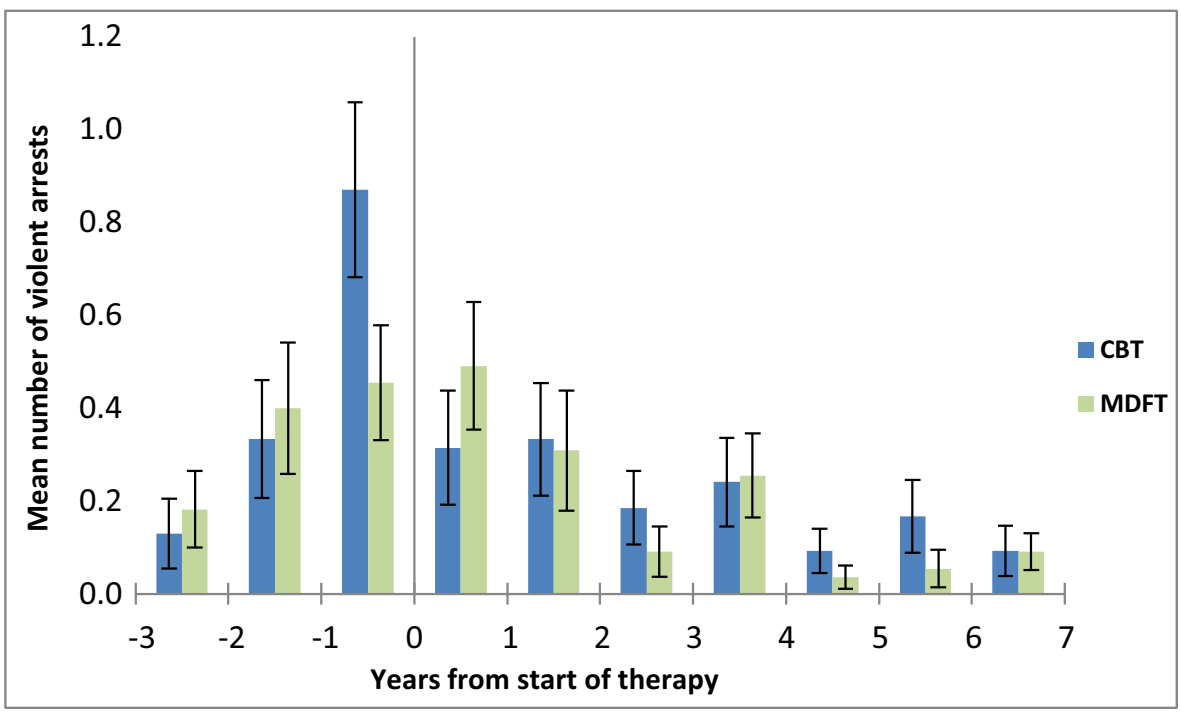

Fig. 2 Mean annual number of police arrests for violent offences, from the start of CBT or MDFT treatment. $\mathrm{CBT}=$ cognitive behavioural therapy; $\mathrm{MDFT}=$ multidimensional family therapy 


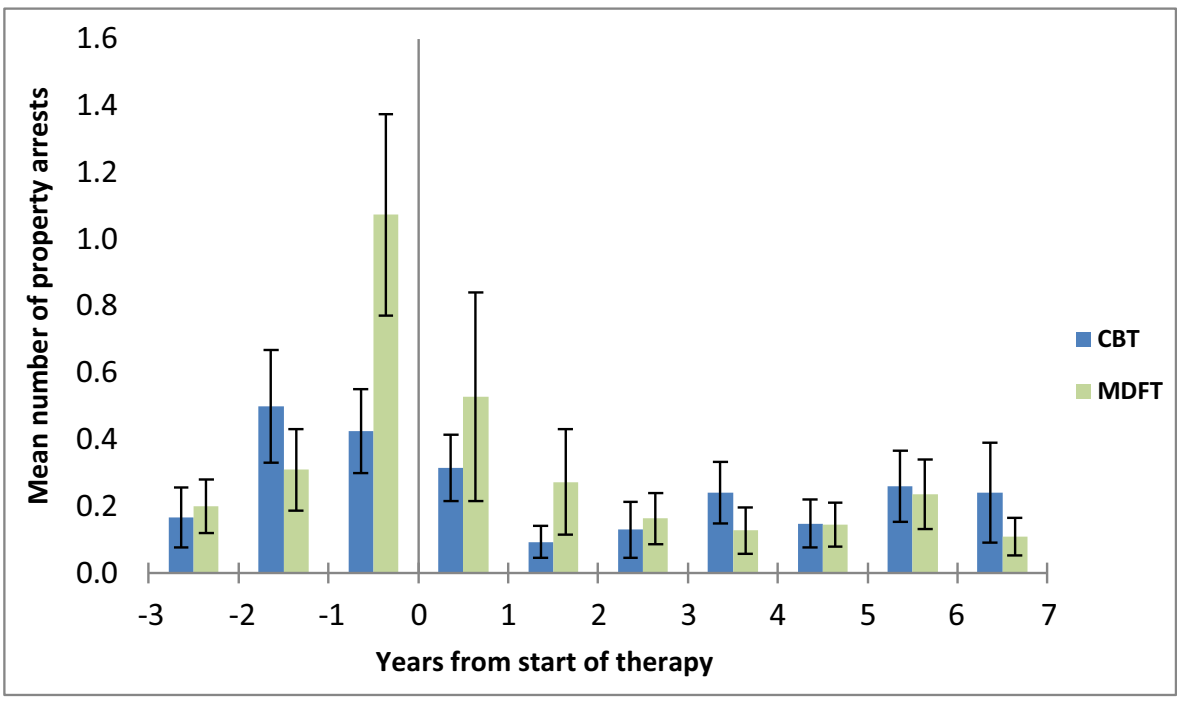

Fig. 3 Mean annual number of police arrests for property offences, from the start of CBT or MDFT treatment. $\mathrm{CBT}=$ cognitive behavioural therapy; $\mathrm{MDFT}=$ multidimensional family therapy

$\mathrm{F}_{4.0,25.6}=8.3, p<0.0001, \eta^{2}=0.07$ ); property (Greenhouse-Geisser $\mathrm{F}_{3.2,338.2}=4.9, p=$ $\left.0.002, \eta^{2}=0.04\right)$. Both violent and property offending did not follow a purely linear decrease trajectory (violence: linear $\mathrm{F}_{1,107}=33.4, p<0.001, \eta^{2}=0.24$, quadratic $\mathrm{F}_{1,107}=$ $10.4, p=0.002, \eta^{2}=0.09,7$ th order $\mathrm{F}_{1,107}=5.7, p=0.019, \eta^{2}=0.05$; property: $\mathrm{F}_{1,107}=9.9$, $p=0.002, \eta^{2}=0.08$, quadratic $\mathrm{F}_{1,107}=12.5, p=0.001, \eta^{2}=0.10$ ): offending rates dropped in the first 3 years after treatment, to remain low afterwards (Figs. 2 and 3). There was no significant difference between treatment groups in decrease of frequency of both violent (Greenhouse-Geisser $\mathrm{F}_{4.0,425.6}=1.6, p=0.16, \eta^{2}=0.02$ ) and property offending (Greenhouse-Geisser $\mathrm{F}_{3.2,338.2}=1.8, p=0.15, \eta^{2}=0.02$ ).

\section{Baseline predictors of a differential treatment effect}

We performed second-order interaction analyses to assess if MDFT and CBT differed from each other in reducing criminal offending when pre-defined baseline characteristics were entered in the calculations: age of the adolescence, crime offence history, severity of cannabis use, a diagnosis of disruptive behaviour disorder status (oppositional defiant disorder (ODD) and/or conduct disorder (CD)) and family functioning (Hendriks et al. 2011; Rigter et al. 2013). None of these variables influenced crime offending rates $(p>0.15)$.

\section{Discussion}

Both MDFT and CBT decreased the number of police arrests and the severity of the criminal offences that were the reason for arrest. The decline was sharp in the first 3 years of follow-up and there was no return to higher levels during the remainder of the 7-year 
follow-up period. These findings appear not to confirm our hypothesis; however, they are consistent with the drop in self-reported criminal offending seen among adolescents from Dutch and Swiss treatment sites - the Dutch adolescents being the same as in the present study (Van der Pol et al. 2017a). Of note, in the study using the self-report data, MDFT outperformed treatment as usual, including CBT, in reducing violent offences, whereas the MDFT and CBT groups did not differ on any offence measure.

We here report on a follow-up period of 7 years. Even with this larger data set, we could not establish any difference in treatment effect between the CBT and MDFT groups of adolescents. Both treatments lowered the incidence of police arrests for total, violent and property offences. As expected, the baseline characteristics did not influence treatment outcome; these results confirm the findings of our previous study Van Der Pol et al. (2018).

The lack of difference between the two treatment groups might suggest that both treatments were equally effective, unlike in other RCT-based investigations (Dakof et al. 2015; Liddle et al. 2011; Rigter et al. 2013; Van der Pol et al. 2017b). However, this conclusion - there was a general treatment effect - cannot be drawn with certainty, as crime offence rates fell markedly in the general population of the Netherlands during the course of our study. Crime offence rates usually increase to the age of 18 , but then decline to lower levels during emerging adulthood (Hill et al. 2016; Moffitt 1993). In other words, although we prolonged the follow-up period to 7 years, which is exceptionally long, and extended the data set, we could not exclude a general population trend as a confounding factor.

The present study relied on police arrest registry measures as a proxy of criminal offending. Recent literature suggests that self-report is the best approach to establish statistically significant differences between treatment groups. In studies of another family therapy, multisystemic therapy (MST), MST - although weakly effective at best-scored better on self-report measures than on crime records measures (Asscher et al. 2014; Fonagy et al. 2018). Of interest, Dutch police-records based crime statistics for adolescents have dropped with roughly $40 \%$ in the past decade, while self-report crime rates decreased with only 10\% (De Waard 2017; Van der Laan et al. 2014). The $40 \%$ registry measure decline falls short of the present study's $87 \%$ reduction in total police-arrest criminal offences for the combined treatment groups across the same period of time. Thus, at least part of the observed police-records based decline in criminal offending rate appears to reflect a treatment effect, for both MDFT and CBT.

The registry measure of criminal offending requires further examination. Why did the prevalence of registry-measured crime offences fall so sharply in the general population in the past decade? Perhaps, police procedures (letting young or first-time offenders walk without a booking) have changed. In addition, growing use of social media and smart phones may have kept youths away from the temptations of the street (De Waard 2017).

Thus, we cannot exclude a general population trend as a confounding factor in the apparent treatment effect. A methodological solution to resolve this impasse would have been to add a waiting-list control group to the trial. This was not an option. It would have been unethical to not offer an effective therapy to youths needing treatment. Another limitation is that the targeted population is primarily addicted with comorbid problem behaviour and high in risk for criminal activities. Therefore, a more severe criminal adolescent population and/or a broader measurement strategy could have given more clarification and a context for the criminal behaviour of the adolescents. 
A strength of the present investigation was that it was embedded in a randomised controlled trial, with the methodological advantages of this type of study design (Weisburd et al. 2001; Welsh et al. 2011). Another strong point, from a youth developmental perspective, was the long timespan of the study and especially the long duration of the follow-up period, which ranged from adolescence to early adulthood, creating an overall developmental perspective of adolescent crime. Following RCT participants up for 7 years is rare in treatment trials.

To generate more insight for the research field, this study should preferably be replicated with a larger sample of adolescents, recruited for criminal offending rather than for abusing cannabis. In a replication study, follow-up periods for self-report and for registry assessments should be the same and more information should be collected on the determinants and the nature of the delinquent behaviour of the youths concerned.

\title{
Conclusions
}

The incidence of police arrests fell after adolescents entered 6-month treatment with MDFT or CBT. The police arrest rate dropped sharply in the first 3 years after treatment entry and remained at close to zero levels in the next 4 years of follow-up. The MDFT and CBT groups did not differ on any measure.

Authors' contributions TvdP and HR conceived the study. HR provided the INCANT data. RV arranged for the research facilities, including access to the police arrest data. TvdP collected the data, which were analysed by MC. HR and TvdP wrote the manuscript, with critical input from MC, LvD and RV.

Funding information The work reported here has been funded by the Ministry of Health, the Netherlands.

Data availability The dataset of this study is available from the corresponding author on reasonable request.

\section{Compliance with ethical standards}

Competing interests HR is a member of the advisory board of MDFT International. Other than this, the authors declare no competing interests.

Ethics approval and consent The Dutch part of the INCANT trial, including the present study, was approved by the medical-ethical committee for research in mental health care settings of the Netherlands (METiGG; registration no. 5238). The adolescent and at least one of his or her parents signed an informed consent to participate in the trial. Access to the police arrest data was approved by WODC, the research and research management institute of the Ministry of Security and Justice of the Netherlands.

Consent for publication Not applicable.

\author{
Abbreviations \\ $A D I, \quad$ adolescent diagnostic interview; \\ CBT, cognitive behavioural therapy; \\ $C D, \quad$ conduct disorder;
}


INCANT, International Cannabis Need of Treatment trial;

MDFT, multidimensional family therapy;

MST, multisystemic therapy;

$O D D, \quad$ oppositional defiant disorder;

$R C T, \quad$ randomised controlled trial;

rmGLM, repeated measure general linear models;

SD, $\quad$ standard deviation;

$T L F B, \quad$ timeline follow-back

Open Access This article is licensed under a Creative Commons Attribution 4.0 International License, which permits use, sharing, adaptation, distribution and reproduction in any medium or format, as long as you give appropriate credit to the original author(s) and the source, provide a link to the Creative Commons licence, and indicate if changes were made. The images or other third party material in this article are included in the article's Creative Commons licence, unless indicated otherwise in a credit line to the material. If material is not included in the article's Creative Commons licence and your intended use is not permitted by statutory regulation or exceeds the permitted use, you will need to obtain permission directly from the copyright holder. To view a copy of this licence, visit http://creativecommons.org/licenses/by/4.0/.

\section{References}

Asscher, J. J., Deković, M., Manders, W., van der Laan, P. H., Prins, P. J. M., \& van Arum, S. (2014). Sustainability of the effects of multisystemic therapy for juvenile delinquents in the Netherlands: effects on delinquency and recidivism. Journal of Experimental Criminology, 10(2), 227-243.

Dakof, G. A., Henderson, C. E., Rowe, C. L., Boustani, M., Greenbaum, P. E., Wang, W., Liddle, H. A. (2015). A randomized clinical trial of family therapy in juvenile drug court. Journal of family psychology, 29(2), 232.

De Waard, J. (2017). Verdampende jeugdcriminaliteit. Justitiele Verkenningen, 43(1).

Fonagy, P., Butler, S., Cottrell, D., Scott, S., Pilling, S., Eisler, I., Wason, J. (2018). Multisystemic Therapy versus management as usual in the treatment of adolescent antisocial behaviour (START): a randomised controlled pragmatic effectiveness superiority trial. The Lancet Psychiatry, 5(2), 119-133.

Galanter, M., Kleber, H. D., \& Brady, K. (2014). The American Psychiatric Publishing textbook of substance abuse treatment. Washington, DC: American Psychiatric Pub.

Girden, E. R. (1992). ANOVA: Repeated measures. Newbury Park: Sage.

Grotevant, H. D., \& Carlson, C. I. (1989). Family assessment: a guide to methods and measures. New York: Guilford Press.

Hartnett, D., Carr, A., Hamilton, E., \& O’Reilly, G. (2017). The effectiveness of functional family therapy for adolescent behavioral and substance misuse problems: a meta-analysis. Family Process, 56(3), 607-619.

Henderson, C. E., Dakof, G. A., Greenbaum, P. E., \& Liddle, H. A. (2010). Effectiveness of multidimensional family therapy with higher severity substance-abusing adolescents: report from two randomized controlled trials. Journal of Consulting and Clinical Psychology, 78(6), 885-897. https://doi.org/10.1037 /a0020620.

Hendriks, V., Van der Schee, E., \& Blanken, P. (2011). Treatment of adolescents with a cannabis use disorder: main findings of a randomized controlled trial comparing multidimensional family therapy and cognitive behavioral therapy in the Netherlands. Drug Alcohol Dependence, 119(1-2), 64-71. https://doi. org/10.1016/j.drugalcdep.2011.05.021. 
Hill, J. M., Blokland, A. A. J., \& van der Geest, V. R. (2016). Desisting from crime in emerging adulthood: adult roles and the maturity gap. Journal of Research in Crime and Delinquency, 53(4), 506-535.

Jansma, J. B. M., \& De Coole, R. L. (1995). Gezinsklimaatschaal: Handleiding [Family Environment Scale: Manual]: Lisse. the Netherlands: Swets \& Zeitlinger BV.

Kirk, D. S. (2006). Examining the divergence across self-report and official data sources on inferences about the adolescent life-course of crime. Journal of Quantitative Criminology, 22(2), 107-129.

Korrelboom, K., \& Ten Broek, E. (2004). Geïntegreerde cognitieve gedragstherapie.[integrated cognitive behavioural therapy]. Coutinho, Muiderberg (The Netherlands).

Liddle, H. A. (2002). Multidimensional family therapy for adolescent cannabis users. Cannabis Youth Treatment (CYT) Series, Volume 5. Rockville: Center for Substance Abuse Treatment, Substance Abuse and Mental Health Services Administration.

Liddle, H. A. (2010). Treating adolescent substance abuse using multidimensional family therapy. In J. Weisz and A. Kazdin (eds.). Evidence-based Psychotherapies for Children and Adolescents (2nd ed., pp. 416432). New York: Guilford Press.

Liddle, H. A., Rowe, C. L., Dakof, G. A., Henderson, C. E., \& Greenbaum, P. E. (2009). Multidimensional family therapy for young adolescent substance abuse: twelve-month outcomes of a randomized controlled trial. Journal of Consulting and Clinical Psychology, 77(1), 12-25. https://doi.org/10.1037/a0014160.

Liddle, H. A., Dakof, G. A., Henderson, C. E., \& Rowe, C. L. (2011). Implementation outcomes of multidimensional family therapy-detention to community: a reintegration program for drug-using juvenile detainees. International Journal of Offender Therapy and Comparative Criminology, 55(4), 587-604. https://doi.org/10.1177/0306624X10366960.

Moffitt, T. E. (1993). Adolescence-limited and life-course-persistent antisocial behavior: a developmental taxonomy. Psychological Review, 100(4), 674-701.

Moos, R. H., \& Moos, B. S. (1994). Family environment scale manual: consulting Psychologists Press.

Moos, R.H., Moos, B.S. (1986). Family Environment Scale Manual. Palo Alto: Consulting Psychologists Press.

Mulder, E., Brand, E., Bullens, R., \& Van Marle, H. (2010). Toward a classification of juvenile offenders: subgroups of serious juvenile offenders and severity of recidivism. International Journal of Offender Therapy and Comparative Criminology. https://doi.org/10.1177/0306624X10387518.

Rigter, H., Pelc, I., Tossmann, P., Phan, O., Grichting, E., Hendriks, V., \& Rowe, C. (2010). INCANT: a transnational randomized trial of multidimensional family therapy versus treatment as usual for adolescents with cannabis use disorder. BMC Psychiatry, 10, 28. https://doi.org/10.1186/1471-244X-10-28.

Rigter, H., Henderson, C. E., Pelc, I., Tossmann, P., Phan, O., Hendriks, V., ... Rowe, C. L. (2013). Multidimensional family therapy lowers the rate of cannabis dependence in adolescents: a randomised controlled trial in Western European outpatient settings. Drug Alcohol Dependence, 130(1-3), 85-93. doi: https://doi.org/10.1016/j.drugalcdep.2012.10.013.

Rowe, C., Rigter, H., Henderson, C., Gantner, A., Mos, K., Nielsen, P., \& Phan, O. (2013). Implementation fidelity of multidimensional family therapy in an international trial. Journal of Substance Abuse Treatment, 44(4), 391-399.

Shaffer, D., Fisher, P., Lucas, C. P., Dulcan, M. K., \& Schwab-Stone, M. E. (2000). NIMH diagnostic interview schedule for children version IV (NIMH DISC-IV): description, differences from previous versions, and reliability of some common diagnoses. Journal of the American Academy of Child \& Adolescent Psychiatry, 39(1), 28-38.

Sobell, L. C., \& Sobell, M. B. (1992). Timeline follow-back: a technique for assessing self-reported alcohol consumption. In: Litten, R.Z., Allen, J.P. (Eds.). Measuring Alcohol Consumption: Psychosocial and Biochemical Methods. (pp. 41-72). Clifton: Humana Press.

Van der Laan, A. M., Goudriaan, H., \& Weijters, G. (2014). Monitor jeugdcriminaliteit: Ontwikkelingen in de aantallen verdachten en strafrechtelijke daders 1997-2012. Cahiers 2014-7. Den Haag: Wetenschappelijk Onderzoeks- en Documentatiecentrum/Ministerie van Veiligheid en Justitie.

Van der Pol, T. M., Henderson, C. E., Hendriks, V., Schaub, M. P., \& Rigter, H. (2017a). Multidimensional family therapy reduces self-reported criminality among adolescents with a cannabis use disorder. International Journal of Offender Therapy and Comparative Criminology, 62(6), 1573-1588.

Van der Pol, T. M., Hoeve, M., Noom, M. J., Stams, G. J. J. M., Doreleijers, T. A. H., Van Domburgh, L., \& Vermeiren, R. R. J. M. (2017b). Research review: the effectiveness of multidimensional family therapy in treating adolescents with multiple behavior problems-a meta-analysis. Journal of Child Psychology and Psychiatry, 58(5), 532-545.

Van Der Pol, T. M., Hendriks, V., Rigter, H., Cohn, M. D., Doreleijers, T. A. H., Van Domburgh, L., \& Vermeiren, R. R. J. M. (2018). Multidimensional family therapy in adolescents with a cannabis use 
disorder: long-term effects on delinquency in a randomized controlled trial. Child and Adolescent Psychiatry and Mental Health, 12(1), 44.

Van der Stouwe, T., Asscher, J. J., Stams, G. J. J. M., Deković, M., \& Van der Laan, P. H. (2014). The effectiveness of multisystemic therapy (MST): a meta-analysis. Clinical Psychology Review, 34(6), 468481.

Weisburd, D., Lum, C. M., \& Petrosino, A. (2001). Does research design affect study outcomes in criminal justice? The Annals of the American Academy of Political and Social Science, 578(1), 50-70.

Welsh, B. C., Peel, M. E., Farrington, D. P., Elffers, H., \& Braga, A. A. (2011). Research design influence on study outcomes in crime and justice: a partial replication with public area surveillance. Journal of Experimental Criminology, 7(2), 183-198.

Winters, K. C., \& Henly, G. A. (1993). Adolescent diagnostic interview schedule and manual (p. b34). Los Angeles: Western Psychological Services.

Publisher's note Springer Nature remains neutral with regard to jurisdictional claims in published maps and institutional affiliations.

Thimo M. van der Pol is a senior researcher at the Amsterdam University Medical Center in the Netherlands. He obtained his $\mathrm{PhD}$ at Leiden Unversity. His research interests include forensic psychiatry, adolescent delinquency/crime, the effectiveness of treatments, systemic/family treatments, treatment mechanisms.

Moran D. Cohn is a senior researcher at the Amsterdam University Medical Center in the Netherlands.

Lieke van Domburgh is a senior researcher at the Amsterdam University Medical Center in the Netherlands.

Henk Rigter is a senior researcher at Leiden University in the Netherlands.

Robert R. J. M. Vermeiren is Professor of Child and Youth Psychiatry at Leiden University, in the Netherlands.

\title{
Affiliations
}

\section{Thimo M. van der Pol ${ }^{1,2} \cdot$ Moran D. Cohn $^{2} \cdot$ Lieke van Domburgh $^{2} \cdot$ Henk Rigter $^{1} \cdot$ Robert R. J. M. Vermeiren ${ }^{1,2}$}

\author{
Moran D. Cohn \\ morancohn@hotmail.com \\ Lieke van Domburgh \\ l.vandomburgh@vumc.nl \\ Henk Rigter \\ rigter.h@kpnmail.nl
}

Robert R. J. M. Vermeiren

r.r.j.m.vermeiren@curium.nl

1 Department of Child and Adolescent Psychiatry, Curium, Leiden University Medical Center, Endegeesterstraatweg 27, 2342 AK Oegstgeest, the Netherlands

2 Department of Child and Adolescent Psychiatry, Amsterdam University Medical Center, Meibergdreef 9, 1105 AZ Amsterdam, The Netherlands 